\title{
Health System in India: Opportunities and Challenges for Improvements
}

\author{
Ramani KV, Mavalankar Dileep \\ Indian Institute of Management, Ahmedabad
}

\begin{abstract}
Health and Socio-economic developments are so closely intertwined that is impossible to achieve one without the other. While the economic development in India has been gaining momentum over the last decade, our health system is at crossroads today. Even though Government initiatives in public health have recorded some noteworthy successes over time, the Indian health system is ranked 118 among 191 WHO member countries on overall health performance. Building Health Systems that are responsive to community needs, particularly for the poor, requires politically difficult and administratively demanding choices. Health is a priority goal in its own right, as well as a central input into economic development and poverty reduction. Health sector is complex with multiple goals, multiple products, and different beneficiaries. India is well placed now to develop a uniquely Indian set of health sector reforms to enable the health system in meeting the increasing expectations of its users and staff. Managerial challenges are many to ensure availability, access, affordability, and equity in delivering health services to meet the community needs efficiently and effectively.
\end{abstract}

In this working paper, we describe the status of our health system, discuss critical areas of management concerns, suggest a few health sector reform measures, and conclude by identifying the roles and responsibilities of various stakeholders for building health systems that are responsive to the community needs, particularly for the poor.

Key words: Availability, Access, Affordability, Equity, Efficiency, Effectiveness. 


\title{
Health System in India: Opportunities and Challenges for Improvements
}

\author{
Ramani KV, Mavalankar Dileep, \\ Indian Institute of Management, Ahmedabad
}

1. Introduction: Health and Socio-economic developments are so closely intertwined that is impossible to achieve one without the other. While the economic development in India has been gaining momentum over the last decade, our health system is at crossroads today. Even though Government initiatives in public health have recorded some noteworthy successes over time (eradicate smallpox and Guineaworm, substantial decline in the number of Leprosy, Polio, and Malaria case, etc [NHP 2002]), our achievements in health outcomes are only moderate by international standards; India is ranked 118 among 191 WHO member countries on overall health performance [WHO, 2000]. A few health statistics are worth mentioning:

Maternal Death and Disability: More than 100, 000 mothers in India die every year, which amounts to 1 maternal death every 5 minutes. What is unfortunate is that more than $75 \%$ of these deaths are preventable if proper medical attention can be provided on time. And, for every maternal death, there are 10-15 maternal disabilities, for lack of medical attention. What is the economic and social impact on maternal death and disability?

Infant and Child Mortality: An average IMR of 70 per 1000 live births and a CMR of 95 per 1000 live births are also very high compared with 5-6 CMR in developed nations. Most of these deaths are also preventable.

HIV/AIDS: India with 5.1 million HIV/AIDS cases (official figures) has the highest number of HIV/AIDS cases as a country outside Africa. HIV/AIDS is hindering decades of health, economic and social progress. Indicators of human development-such as child mortality, literacy, and food production- are slipping as the disease ravages families, communities, economies, and health systems in heavily affected countries.

Non-Communicable Diseases: Non communicable diseases are on the rise. 25 million cardiovascular diseases, 25 million cases of Diabetes, 2.4 million cases of Cancer, and so on [Kurkure, 2005].

Urban Health: Urbanization is an important demographic shift worldwide. Today, nearly $50 \%$ of the world population is urban. India's urban population of 300 million represents $30 \%$ of our population. Government of India started urban health planning only 10 years ago in the $9^{\text {th }}$ Five Year Plan document [GoI, 2003]. An urban slum growth rate of $5 \%$ is causing serious concern for the civic and health authorities in municipalities and towns. Health of urban poor and its implications on the entire urban population should be analyzed and an appropriate urban health policy should be arrived at.

Environmental health: Contaminated water and poor sanitation is responsible for large proportion of diseases in India. Poor hygiene and sanitation account for $9 \%$ of all deaths and an estimated 27.4 million years of life are lost each year in India. Unfortunately in spite of such staggering ill health caused by poor hygiene and sanitation scant attention is being paid to its improvement. Currently only about $20 \%$ of rural households have toilets. The rate of increase of toilets in rural area is slow that it will take about 80 years to have $100 \%$ coverage in rural areas. (Mavalankar, 2004). Given the situation in sanitation and hygiene is one of the urgent needs for improving rural health.

Healthcare Insurance: The Government's contribution to the total healthcare expenditure is only $20 \%$, and therefore out-of-pocket expenditure is as high as $80 \%$ (see next section for details). 
The cost of healthcare is increasing rapidly. A large majority of our population cannot afford healthcare expenses. In India, there are five forms of healthcare insurance- private insurance, social insurance, employer-provided cover, community insurance schemes, and government healthcare spend. Only 3-4 \% of our population is insured. Insurance has grown by $100 \%$ in the last 2 years. It is estimated that about 160 million people will be covered by 2010 , which is less than $15 \%$ of the population.

Support Services: Support services such as blood banking, ambulance services, communication, medical-social work, hospital waste management etc are very essential to provide good quality of health and medical services. Indian healthcare sector lacks good support services. For example, there is a severe shortage of blood in many rural areas, ambulance service is unreliable and medical infection control and waste disposal are pathetic. In such a situation, it is very difficult to provide good quality and safe medical services. Thus improving support services should form an important agenda for improving healthcare delivery.

\section{Building Health Systems:}

Building Health Systems that are responsive to community needs, particularly for the poor, requires politically difficult and administratively demanding choices

Health is a priority goal in its own right, as well as a central input into economic development and poverty reduction. The WHO Report on "Investing in Health for Economic Development" by Jeffrey Sachs, Manmohan Singh et al [Sachs Jeffrey, 2001], suggests that for developing countries like India, health policies should focus on

- Scaling up financial resources (e.g.: Public-private partnership), and

- Tackling the non- financial obstacles in service delivery (e.g.: logistics, HR, and governance issues)

Health and socio-economic development follow each other. Table 1 given below gives a comparison of the economic status, expenditure on health, and health outcomes in High Income, Middle Income, and Low Income countries.

The macroeconomic scenario of the Indian Health sector is not very encouraging. The total annual expenditure on Health is around Rs. 110,000 Crores, and it accounts for $5.2 \%$ of our GDP. However, public health investment has declined from $1.3 \%$ of GDP to $0.9 \%$ by 2001 (comparable figures for China, Sri Lanka and Nepal are $2 \%, 1.8 \%$ and $1.6 \%$ respectively). Government share of the total expenditure is only $17 \%$, and therefore out-of-pocket expenditure is as high as $83 \%$. Central contribution to overall public health spending in States is limited to 15 $\%$. Central budgetary allocation for health has remained static at $1.3 \%$ of the total central budget. State budgetary allocations have declined from $7 \%$ to less than $5.5 \%$ in many states. There is therefore an urgent need to scale up financial resources in the health sector. 
Table 1

Economic Status, Expenditure on Health, and Health Outcomes

\begin{tabular}{|c|c|c|c|c|c|c|c|c|c|}
\hline \multirow[t]{2}{*}{ Country } & \multicolumn{4}{|c|}{ Economic Status } & \multicolumn{3}{|c|}{ Expenditure on Health } & \multicolumn{2}{|c|}{ Health Outcomes } \\
\hline & $\begin{array}{c}\text { GNP per } \\
\text { capita } \\
\$\end{array}$ & $\begin{array}{l}\text { Popu- } \\
\text { lation } \\
\text { Mill } \\
\text { (2002) }\end{array}$ & $\begin{array}{l}\text { Bill \$ } \\
\text { (2002) }\end{array}$ & $\begin{array}{c}\text { GDP } \\
\text { Growth } \\
\% \\
2001-02\end{array}$ & $\begin{array}{l}\% \text { GDP } \\
(2000)\end{array}$ & $\begin{array}{l}\% \text { GDP } \\
(2000)\end{array}$ & $\begin{array}{c}\text { Total } \\
\text { per } \\
\text { capita } \\
\$ \\
(2000)\end{array}$ & $\begin{array}{c}\text { CMR } \\
\text { per } \\
1000 \\
\text { live } \\
\text { births } \\
(2001)\end{array}$ & $\begin{array}{c}\text { MMR } \\
\text { per } \\
100,000 \\
\text { live } \\
\text { births } \\
(1995)\end{array}$ \\
\hline \multicolumn{10}{|c|}{ High Income Countries (Sample) } \\
\hline Switzerland & 37930 & 7 & 274 & -0.2 & 5.9 & 4.8 & 3573 & 6 & 8 \\
\hline USA & 35060 & 288 & 10110 & 2.3 & 5.8 & 7.2 & 4499 & 8 & 12 \\
\hline Japan & 33550 & 127 & 4266 & -0.7 & 6.0 & 1.8 & 2908 & 5 & 12 \\
\hline UK & 25250 & 59 & 1486 & 1.5 & 5.9 & 1.4 & 1747 & 7 & 10 \\
\hline Germany & 22670 & 82 & 1870 & 0.2 & 8.0 & 2.6 & 2422 & 5 & 12 \\
\hline Canada & 22300 & 31 & 701 & 3.3 & 6.6 & 2.5 & 2058 & 7 & 6 \\
\hline France & 22010 & 59 & 1343 & 1.0 & 7.2 & 2.3 & 2057 & 6 & 20 \\
\hline Australia & 19740 & 20 & 387 & 3.5 & 6.0 & 2.3 & 1698 & 6 & 6 \\
\hline Italy & 18960 & 58 & 1098 & 0.4 & 6.0 & 2.1 & 1498 & 6 & 11 \\
\hline \multicolumn{10}{|c|}{ Middle Income Countries (sample) } \\
\hline Mexico & 5910 & 101 & 597 & 0.7 & 2.5 & 2.9 & 311 & 29 & 65 \\
\hline Malaysia & 3540 & 24 & 86 & 4.2 & 1.5 & 1.0 & 101 & 8 & 39 \\
\hline Brazil & 2850 & 174 & 498 & 1.5 & 3.4 & 4.9 & 267 & 36 & 260 \\
\hline S. Africa & 2600 & 44 & 114 & 3.0 & 3.7 & 5.1 & 255 & 71 & 340 \\
\hline Thailand & 1980 & 62 & 122 & 5.2 & 2.1 & 1.6 & 71 & 28 & 44 \\
\hline China & 940 & 1281 & 1210 & 8,0 & 1.9 & 3.4 & 45 & 39 & 60 \\
\hline Sri Lanka & 840 & 19 & 16 & 3.0 & 1.8 & 1.8 & 31 & 19 & 60 \\
\hline \multicolumn{10}{|c|}{ Low Income Countries (sample) } \\
\hline Indonesia & 710 & 212 & 150 & 3.7 & 0.6 & 2.1 & 19 & 45 & 470 \\
\hline India & 480 & 1048 & 502 & 4.4 & 0.9 & 4.3 & 23 & 93 & 440 \\
\hline Pakistan & 410 & 145 & 59 & 4.4 & 0.9 & 3.2 & 18 & 109 & 200 \\
\hline Bangladesh & 360 & 136 & 49 & 4.4 & 1.4 & 2.4 & 14 & 77 & 600 \\
\hline
\end{tabular}

Source: World development report 2004, The World Bank

Health is a state subject in India. However, many states do not have a clear health policy. The strategies of the states are mostly guided by the National Health Policy and national health programs. There is no systematic effort at the state level to plan, and monitor the delivery of health services. Health services continue to be supply pushed than demand driven.

In short, managerial challenges are many to ensure availability, access, affordability, and equity in delivering health services to meet the community needs efficiently and effectively.

\section{Availability of health services:}

Public Health Infrastructure: Between 1950 and 2000, the rural health infrastructure (SC/PHC/CHC) has gone up from 725 facilities to more than 163,000 [Mavalankar and Ramani, 2005], consisting of 4000 rural sub district hospitals (called Community Health Centres-CHCs), 24000 Primary Health Centres (PHCs), and 135,000 sub health Centres (SCs). Yet, there is a shortfall of $16 \%$ in the number of $\mathrm{PHCs} / \mathrm{SCs}$ and as high as $58 \%$ in the case of CHCs.

Public health infrastructure is far from satisfactory as the delivery of services is hampered by several policy and management constraints [Mavalankar, Ramani, and Shaw, 2003)], of particular concerns being 
- Non-availability of Staff

- Weak referral system

- Recurrent funding shortfalls

- Lack of accountability for quality of care

- Poor logistics management of supply of medicines and drugs

All the above mentioned concerns have been repeatedly mentioned in several meetings and documents for the past several years. Yet, the utilization of the massive public health infrastructure is abysmally low. Availability and access to public health facilities is very poor for women, children, and the socially disadvantaged sections of our society. The past unsatisfactory performance of our public health system in rural areas is forcing even the poor to seek healthcare from the private sector. The data shows that only $20 \%$ of outpatient and $45 \%$ for inpatient care is obtained from government health infrastructure while the rest is obtained from private sources.

Under RCH-II programme government is refocusing on primary and rural health services. It has decided to provide 24 hour services, seven days a week, in $50 \%$ of all PHCs over the next five years. Government has also decided to operationalize all designated first referral units in rural areas under RCH-II programme.

Private Healthcare: The private sector is responding aggressively to meet the healthcare demands. Several studies have shown that people in general (rich or poor) have a preference to seek healthcare services from the private sector. Use of government facilities is mostly for indoor care, governed by the decisions on cost of care more than the quality (user perceptions).

Since the Government has not yet laid down any mandatory requirements for registering private healthcare facilities; it is very difficult to get reliable estimates of private health infrastructure in the country. Even though the scale of operations of the private sector is not clear, it is believed that private sector accounts for $67 \%$ of the total number of 30,000 hospitals and $33 \%$ of the total number of 1,000,000 beds. Also, the private sector accounts for over 60 percent of the 5 million doctors in the country. Most of the services offered by the private sector are for secondary and tertiary care, and not much for preventive healthcare.

Based on the above estimates of public and private healthcare infrastructure, India has only about 100 beds per 100,000 populations against the WHO norms of 300 beds per 100,000. The number of doctors per 1000 population is also well below the WHO norms. The demand supply gap is therefore large. Investment required to bridge the gap in the next 10 years could range from Rs. 100,000 crore to Rs.140,000 crore, as can be seen from Table 2 below [CII- McKinsey]. The sector can also create huge income and employment growth in 10 years.

Table 2

Investments needed in Health Sector: Next 10 years

\begin{tabular}{|l|l|}
\hline \multicolumn{1}{|c|}{ Investment } & \multicolumn{1}{c|}{$\begin{array}{c}\text { Amount } \\
\text { ( Rs. '000 crore) }\end{array}$} \\
\hline Secondary Beds & $60-90$ \\
\hline Tertiary Beds & $30-40$ \\
\hline Medical Colleges & $2-3$ \\
\hline Nursing Schools & $2-3$ \\
\hline Other Health Professionals $(*)$ & $2-4$ \\
\hline Total & $100-140$ \\
\hline
\end{tabular}

$(*)$ Pharmacists, technicians, administrators etc. 


\section{Affordability:}

As mentioned earlier, the utilization of public health facilities is only about $20 \%$ for outpatient services and $45 \%$ for inpatient care. In such a situation, poor people are forced to seek healthcare services from the private sector by paying high user fee. This partially explains our out-of-pocket expenditure on health at 80 percent.

Health Insurance is one option to address concerns on affordability. Regional licensing of Health Insurance business like in the US, and Health Insurance schemes like Yeshasvini, Arogya Bhagya Yojana, Arogya Bhadrata are worth exploring. A detailed analysis of the costs and benefits of the Employee State Insurance (ESI) scheme of the Ministry of Labor also would be helpful. The Government should facilitate the growth of private, social and community insurance to improve affordability.

Cost of care can also be contained if the service levels in public sector can be substantially improved, referral systems enforced and the unfinished agenda of controlling infectious diseases achieved [Rao Sujatha, 2004]. The existing financing and payment systems are not suitable for countering market failures typical of insurance.

Insurance services without availability of reasonable quality healthcare service delivery will not serve the intended purpose [Bhat Ramesh, and Saha Somen 2004]. It is necessary to ensure availability of health services for any insurance scheme to succeed.

\section{Access:}

Availability of health infrastructure is only a necessary condition, but not sufficient, to guarantee delivery of services. Access to services is an equally important determinant in meeting the healthcare needs of people, especially those in rural areas. Ambulance services to transport the serious patients to referral centres are very minimal. Public transportation between $\mathrm{PHC} / \mathrm{CHC}$ to the District/State hospitals is irregular and infrequent. Private transport is expensive. Many $\mathrm{PHCs} / \mathrm{CHCs}$ do not even have telephones or wireless communications. The existing public health system in rural areas has therefore become very unreliable and undependable for access to healthcare facilities especially in emergencies.

Access to heath facilities is equally worse in some large towns and urban areas, since the heterogeneous urban population have different expectations from the urban health systems. Even though urban areas have more health facilities, and better transportation than rural areas, the location, operating time and other characteristics of public health facilities do not favor the urban slum populations accounting for 35-45 \% of urban population in India.

Telemedicine is being cited as an option worth exploring. Telemedicine infrastructure consists of a Telemedicine Specialist Centre (TSC) at a large hospital connected to a Telemedicine Consultation Centre (TCC) in a CHC/District hospital. Since 75 percent of all treatments do not require surgical interventions, telemedicine infrastructure can theoretically address $75 \%$ of our healthcare needs. Telemedicine infrastructure can also support Continuing Medical Education (CME) for professional development of doctors, as well as facilitate health promotion activities. Indian Space Research Organization (ISRO) is playing a vital role by providing VSAT connectivity for telemedicine centres.

Effective use of regular and mobile telephone can also improve access and quality of healthcare in rural areas. Example, a $\mathrm{PHC} / \mathrm{CHC}$ doctor can consult a specialist on phone at a district Head quarters or in a medical college. 


\section{Equity:}

Over and above availability, access, and affordability concerns, a fourth determinant of the quality of healthcare services focuses on equity of services.

In the period when centralized planning was accepted as a key instrument of development in the country, the attainment of an equitable distribution was considered one of the main objectives. Despite this conscious focus in the development process, the attainment of health status differs significantly across states as shown in Table 3 and Table 4 below [NHP 2002].

While inequality exists between low-high performing states, as well as between populations with different socio-economic status, inequality concerns between the rural and urban areas are of a different nature. The dimensions of equity assume larger proportions in urban areas because of socio-economic and cultural diversity of urban population. Indian population growth is characterized by the 2-3-4-5 syndrome: overall population growth at $2 \%$, urban population growth at $3 \%$, mega cities growth at $4 \%$, and slum population growth at $5 \%$. Equity concerns in urban health have to address these realities as well.

Health insurance, mentioned earlier, can also address equity concerns. With greater coverage through insurance, equity in healthcare will improve through effective cross subsidization.

Table 3

\section{Differentials in Health Status}

\begin{tabular}{|l|l|l|l|l|l|l|l|}
\hline Sector & $\begin{array}{l}\text { Population } \\
\text { BPL (\%) }\end{array}$ & IMR & $\begin{array}{l}<5 \text { Mort- } \\
\text { ality }\end{array}$ & $\begin{array}{l}\% \\
\text { Children } \\
\text { underwt }\end{array}$ & MMR* & $\begin{array}{l}\text { Leprosy } \\
\text { Cases } \\
/ 10000\end{array}$ & $\begin{array}{l}\text { Malaria } \\
\text { cases }\end{array}$ \\
\hline India & 26.1 & 70 & 94.9 & 47 & 408 & 3.7 & 2200 \\
\hline Rural & 22.09 & 75 & 103.7 & 49.6 & - & - & - \\
\hline Urban & 23.62 & 44 & 63.1 & 38.4 & - & - & - \\
\hline Better performing States \\
\hline Kerala & 12.72 & 14 & 18.8 & 27 & 87 & 0.9 & 5.1 \\
\hline Maharashtra & 25.02 & 48 & 58.1 & 50 & 135 & 3.1 & 138 \\
\hline TN & 21.12 & 52 & 63.3 & 37 & 79 & 4.1 & 56 \\
\hline Low Performing States & 47.15 & 97 & 104.4 & 54 & 498 & 7.05 & 483 \\
\hline Orissa & 42.60 & 63 & 105.1 & 54 & 707 & 11.83 & 132 \\
\hline Bihar & 15.28 & 81 & 114.9 & 51 & 607 & 0.8 & 53 \\
\hline Rajasthan & 31.15 & 84 & 122.5 & 52 & 707 & 4.3 & 99 \\
\hline UP & 37.43 & 90 & 137.6 & 55 & 498 & 3.83 & 528 \\
\hline MP
\end{tabular}


Table 4

Differentials between Social Groups

\begin{tabular}{|c|c|c|c|}
\hline Indicator & IMR/1000 & $<\mathbf{5 M o r t a l i t y / 1 0 0 0}$ & $\begin{array}{c}\text { \% Children } \\
\text { underweight }\end{array}$ \\
\hline India & 70 & 94.9 & 47 \\
\hline Scheduled Castes & 83 & 119.3 & 53.5 \\
\hline Scheduled Tribes & 84.2 & 126.6 & 55.9 \\
\hline Other Disadvantaged & 76 & 103.1 & 47.3 \\
\hline Others & 61.8 & 82.6 & 41 \\
\hline
\end{tabular}

\section{Management Challenges:}

Management is all about planning, monitoring and control. Effective and efficient management relies on routine data collection, compilation, analysis, and estimation of performance indicators at regular intervals, and not on adhoc and unthoughtfull data collection for statutory reporting needs. Managerial solutions may lie in the areas on organizational changes to respond to client needs, decentralization, granting autonomy, logistics management, resource mobilization through public-private partnership, management information system and so on. Many of these solutions are attempted through Health Sector Reforms in developing countries.

Health sector is complex involving several stakeholders, multiple goals, multiple products and different beneficiaries. Health sector reforms have to be carefully designed and implemented. Health System change is political and calls for behavioral changes. Below in Table 5 we list critical areas of management concerns, causes amenable to health sector reforms and relevant reform levers [Krasovec and Shaw, 2000] to address the managerial challenges in delivering quality health services at affordable cost.

Table 5

\section{Areas of Concern and Relevant Reform Levers}

\begin{tabular}{|l|l|l|}
\hline Area of Concern & Causes amenable to reforms & Relevant reform levers \\
\hline Non-availability of staff & $\begin{array}{l}\text { Outdated policies \& incentive } \\
\text { structure } \\
\text { Role of Paramedics limited }\end{array}$ & $\begin{array}{l}\text { Organizational change and } \\
\text { policy reforms } \\
\text { Empowerment of nurses and } \\
\text { paramedical staff } \\
\text { Decentralization }\end{array}$ \\
\hline Weak referral system & Lack of integration & $\begin{array}{l}\text { Strengthen communication and } \\
\text { transport infrastructure } \\
\text { Behavioral change } \\
\text { Health Awareness }\end{array}$ \\
\hline Poor service delivery & $\begin{array}{l}\text { Weak logistics management } \\
\text { Underutilization of resources }\end{array}$ & $\begin{array}{l}\text { Data based management } \\
\text { planning, monitoring, } \\
\text { control and } \\
\text { Granting autonomy }\end{array}$ \\
\hline Funding shortfalls & Absolute shortfall \\
quality of care & Systemic inefficiencies & $\begin{array}{l}\text { Public-Private Partnerships } \\
\text { Increasing government health } \\
\text { budgets } \\
\text { Organizational change }\end{array}$ \\
\hline Lack of transparency & $\begin{array}{l}\text { Obsession with FP targets } \\
\text { health system } \\
\text { e-Governance }\end{array}$ \\
\hline
\end{tabular}




\section{Health Sector Reforms:}

Health sector is complex with multiple goals, multiple products, and different beneficiaries. Peter Berman [Berman, 1995] describes health sector reform as "sustained, purposeful change to improve the efficiency, equity, and effectiveness of the health sector. The implementation of large-scale health system reform demands political sensitivity, strategic thinking and management capacity of a high order. In practice, the application of health system reforms takes a wide variety of shapes by combining different components into different configurations.

The Indian public health system has so far remained largely unaffected by the appetite for largescale reform affecting so may other countries, and thereby has avoided many of the pitfalls, which early reformers experienced. Experience of nine states in India which undertook health sector reforms are well documented [GoI, 2004]. India is well placed now to profit from others' experience and to develop a uniquely Indian set of reforms to enable the health system better to meet the increasing expectations of its users and staff. The second advantage India has are the highly competent professionals and reputed management institutes that can provide technical support to the reform efforts by rigorously analyzing the experiences and ongoing efforts. The third advantage India has in health reform is that the economic reforms started in 1991 have yielded good results thus creating a positive political and social environment for public system reforms in general. Above all, the Government of India has demonstrated political will to improve the delivery of health services in our goal for greater socio economic development.

Below we illustrate a sample of three major reforms successfully implemented in India in two Indian States, namely, Tamil Nadu, Madhya Pradesh, and Andhra Pradesh. It should be realized that replication of these reform initiatives on a nation-wide scale needs careful planning and political commitment.

Tamil Nadu Medical Services Corporation: ( Supply of Medicines \& Drugs)

Tamil Nadu Medical Services Corporation (TNMSC) has implemented an excellent logistics management system to coordinate the activities of purchase, storage, and distribution of drugs and medicines in Tamil Nadu [TNMSC, 2003]. It deals with 75 vendors for 600 items for an annual purchase of Rs .120 crores. TNMSC has ensured ready availability of quality drugs and medicines in more than 11,000 government medical institutions throughout the state which includes 9000 sub health centres, 1500 PHCs, 250 Taluka Headquarter hospitals, and 250 veterinary institutions. TNMSC has expanded its activities to improve the state of health system in TN by managing a master health check up scheme at the Government general hospital, Chennai; managing the procurement and services of CTSCANs in all district hospitals, managing a special class maternity ward in the Institute of Obstetrics and Gynecology at Chennai on a very nominal fee fixed by the government, and so on. TNMSC is now an ISO 9001: 2001 company. Several other states including Maharashtra and Rajasthan are already planning to follow the TNMSC example.

Rogi Kalyan Samit : (Augmenting primary health care services)

In most developing countries, provision of basic primary healthcare services is a major concern of the government and decision makers. With growing population and paucity of resources, primary health care has often not met the expectations of the people at large. It is in this context that a pilot project Rogi Kalyan Samiti [RKS,2002] was taken up in Indore, MP. RKS was constituted by including people's representatives with a few government officials. RKS was given full control of the Maharaja Yashwantrao Hospital (MYH), and was given the mandate to take any policy decisions to improve the functioning of MYH. To augment its resources, RKS was authorized to levy user charges for the services provided by the hospital. MYH also underwent administrative restructuring. Improvements in the efficiency of doctors, arresting the deterioration of the hospital, marked improvements in the condition of the medical institution, and an increase in the number of patients coming to MYH are some of the achievements of RKS. Following its success, 
the system was replicated in over 450 government hospitals in all the districts in MP. Other states, including Rajasthan and Gujarat have evidenced keen interest to follow the RKS example.

\section{Telemedicine project:}

Among the many telemedicine centres functioning in India, the Telemedicine Consultation Centre (TCC) at a socio-economically backward district of Mehaboobnagar in Andhra Pradesh state deserves a special mention [Ramani, 2004]. Mehaboobnagar is one of the poorest districts in AP, and is situated about $100 \mathrm{Kms}$ from the state capital, Hyderabad. The autonomy enjoyed by the Mehaboobnagar district hospital under a World Bank assisted project facilitated the state health authorities to enter into a public-private partnership to improve the delivery of health services in Mehabbobnagar through a TCC. Patients now present themselves for lab and radiological investigations at the TCC in the district hospital, which scans and transmits the images to the Telemedicine Specialist Centre (TSC) located in a Private Hospital in Hyderabad. The specialists at TSC interact with the patient and the medical staff at TCC, views the lab reports, carries out live radiological investigations by viewing the transmitted images, and recommend an appropriate line of treatment. This facility is also used by the general practitioners and other consultants at TCC to get second/special opinion from super specialists at the TSC to confirm diagnosis, plan treatment, provide acute interventional plan, as well as to prevent and respond to typical disease patterns in the district.

\section{Recommendations:}

Based on the analysis of the health situation we give a few recommendations for various stakeholders in the health sector.

- Central and state governments:

Protecting the poor against ill health and exploitation: The government has to improve availability, equity and quality of healthcare services, as well as ensure basic care to the poor and the marginalized.

Promote social health insurance: Government should encourage social health insurance which are low cost subsidized insurance packages specifically developed for the poor and lower socio-economic classes. In this connection, the government should encourage the initiatives by NGOs like SEWA, and other similar organizations on no profit basis and exempt such groups from minimum capital requirements.

Scale up financial resources: Funding of public health services needs substantial increases, not only to bridge the current gap but to counteract the effects of chronic under-funding for the last several years. Special attention has to be made to non-salary component of expenditure such as repair and renovation of health facilities, medicines and consumables, equipment, vehicles, and communication. .

Improve management and accountability of public health services: The government has to substantially improve the management information system and accountability mechanism so that the health professionals perform their functions adequately. This will require improving management capacities in the health systems at various levels and through training and creating new posts of management positions.

Ensure quality improvement through standards and accreditations: The government should set up standards for hospitals and health centres at various levels. It should catalyze the development of a system of accreditation of health facilities in the public as well as in private sector. The accreditation status of the hospitals should be widely disseminated. Quality improvement efforts should also include non-clinical and support services. 
- Corporate sector:

Corporate social responsibility (CSR): The corporate sector should continue to play an active role in building health systems to improve the delivery of health services. The corporate sector has a responsibility to serve the economically weaker sections of our society, without compromising on quality of service. Other areas of CSR include social health insurance, telemedicine, and health check up camps in remote areas, through public private partnership. CSR should form part of a long term strategy of the corporate sector.

Corporate sector should provide high quality evidence based medical services at reasonable costs. If possible it should develop mechanisms of cross subsidizing the poor through earnings from well-off sections of the society; the case of Aravind Eye Hospital in providing free and subsidized services to almost $60 \%$ of its patients is worth taking note of. Using the "bottom of pyramid" approach, the corporate sector can make reasonable profit by serving the needs of the poor.

Advocacy: Given the rapidly increasing strength of India corporate sector and its growing influence with the government, organizations such as CII and FICCI can play a very effective role of advocating with central and state governments, MCI, NCI etc to expedite the needed change in the policies, programme design and implementation.

- Non-governmental and non-profit sector:

This sector should work closely with the government to ensure better access to health services by the poor. They should also expand their focus from medical services to prevention and promotional activities. As NGOs work closely with the community and especially with disadvantaged groups, they can actively help convey the needs and voice of the poor to the policy makers for improved delivery of demand driven healthcare services, as against the current practices of supply pushed healthcare services.

- Public Private Partnership (Multi-stakeholder partnership):

Given the complex nature of health systems and the diversity of needs and expectations from a large heterogeneous population belonging to various socio-economic and cultural groups, no single agency can satisfactorily address the health needs. Hence governments, corporate sectors, NGOs and other sectors of societies have to enter into mutually beneficial partnership to serve the health needs of the poor and the lower income groups. These partnerships have to be well thought out, structured and open to independent assessment to ensure transparency and results.

Such partnerships should also be explored in the areas of preventive and promotive healthcare as well as support services such as blood transfusion, ambulance, communication services, medical-social work etc.

- Role of Academic and Research Institutions:

Medical and Nursing Colleges: Medical education should include new areas of clinical practices, and respond to the rapidly changing health scenario in the country. These institutions should facilitate updating the technical knowledge of the existing medical professionals through continuing medical/health education.

Bio-medical research organizations: These organizations would be keen to improving the medical technology in the country. They can help indigenize global technologies and make them available at a very low cost. The initiatives taken by the pharmaceutical sector in this direction need to be followed by the manufacturers of medical equipment and devises. With 
the emergence of WTO, indigenous medical bio-research will become a necessity and offer India a competitive advantage for attracting global research opportunities.

Public health and management training institutions: These institutions can play a vital role in helping improve the quality of the public health in the country as well as improve the management of health services. They can contribute to improving the effectiveness and efficiency in the public health and hospital sectors. These institutions can help adapt lessons from developing countries such as Sri Lanka and Malaysia as well as developed countries such as Germany and Canada which have very effective public health and medical services.

Management institutions such as the Indian Institute of Management, Ahmedabad, which has been engaged in health management research and consulting activities over the last 30 years, can and should contribute towards building health systems which are responsive to community needs.

\section{References}

Berman Peter (1995): "Health Sector Reform in Developing Countries: Making Health Development Sustainable", Boston, Harvard University Press.

Bhat Ramesh and Saha Somen: "Health Insurance Not a panacea", Economic and Political Weekly, August 14, 2004, pages 3667 - 3670.

CII-McKinsey \& Company: "Healthcare in India: The Road Ahead",

Government of India (2004): Health Sector Reforms in India, Initiatives from Nine States, August 2004 , Bureau of Planning, Directorate General of Health Services, Ministry of Health and Family Welfare, Government of India, New Delhi.

Government of India (2003), Ninth Five Year Plan: 1997-2002, Government of India

Krasovec Katherine and Shaw Paul R (2000); "Reproductive Health and Health Sector Reform Linking Outcomes to Action" World Bank Institute, The World Bank, Washington, D.C. USA

Kurkure Arun (2005), "Onco care Systems in India", Oncology Tomorrow, Pre Conference Event, $92^{\text {nd }}$ Indian Science Congress, Ahmedabad, January 3-7, 2005.

Mavalankar Dileep, Ramani KV V. et al (2005). "Building Infrastructure to Reach and Care for the Poor: Trends, Obstacles and Strategies to overcome them." Working Paper 2005-03-01, March 2005, IIM Ahmedabad.

Mavalankar Dileep, Ramani KV, Jane Shaw (2003): “ Management of RH Services in India and the Need for Health System Reform.” Working Paper 2003-09-04, IIMA .

Mavalankar Dileep, Manjunath Shankar (2004): Chapter 13, pp.314-324, Sanitation and Panchayats in Infrastructure in "India Infrastructure Report 2004: Ensuring Value for Money", Oxford University Press.

National Health Policy (2003)

Ramani KV (2004): "IT Enabled Applications in Government Hospitals, India: Illustrations of telemedicine, e-governance, and BPR", IEEE Proceedings of the International Conference on System Sciences, Hawaii, January 5-8, 2004. 
Rao Sujatha (2004). "Health Insurance Concepts, Issues and Challenges", Economic and Political Weekly August 21, 2004, 3835- 3844

RKS (2003): "Rogi Kalyan Samithi, An Innovative Project for the Management of Public Hospitals through Community Participation in the State of Madhya Pradesh'

Sachs, Jeffrey D, et al (2001). "Macroeconomics and Health: Investing in Health for Economic Development," Report of the Commission on Macroeconomics and Health

TNMSC (2003): Tamil Nadu Medical Services Corporation Limited, $10^{\text {th }}$ Annual Report, 200304.

WHO (2000): "Health Systems: Improving performance", The World Development Report 2000, WHO, Geneva

World Development Report (2004), The World Bank, Washington DC. 